\title{
Depression: point-prevalence and risk factors in a North Cyprus household adult cross-sectional study
}

\author{
Mehmet Çakıcl ${ }^{1 *}$, Özlem Gökçe ${ }^{1}$, Asra Babayiğit ${ }^{1}$, Ebru Çakıcl ${ }^{1}$ and Ayhan $\mathrm{Eş}^{2}$
}

\begin{abstract}
Background: Depression is one of the most common diagnosed psychiatric disorders in the world. Besides individual risk factors, it is also found that environment and socio-cultural factors are the other main risk factors for depression. In this article, the results of the 2016 national household survey of depression in North Cyprus (NC) are presented. The aim of the study is to determine the prevalence and possible risk factors of depression in NC households.

Methods: The study was conducted between April and June 2016, the sample consisting of Turkish-speaking individuals between 18 and 88 years of age living permanently in NC. A multi-stage stratified (randomized) quota was used in the survey, and 978 people were selected according to the 2011 census. A 21 item questionnaire prepared by the researchers and a Turkish version of the Beck Depression Inventory scales were used for obtaining data.

Results: This cross-sectional study found a point prevalence of $23.4 \%$ for relatively high BDI scores $(\geq 17)$ suggesting clinical depression. Being female, a widow, unemployed, having a limited education and low income level, having a physical illness, living alone, and using illicit substances were defined as possible risk factors for depression.

Conclusions: When we consider the world prevalence, NC has one of the higher depression prevalence. NC has environmental and socio-cultural characteristics such as a history of war, migration and colonization, high unemployment rates, socioeconomic problems, similar to other extremely high prevalence depression countries and regions, which give a strong indication of the importance of socio-cultural factors on depression.
\end{abstract}

Keywords: Prevalence, Major depression, Risk factors, Socio-cultural risk factors

\section{Background}

Depression is one of the most commonly diagnosed psychiatric disorders and is ranked as the 4th main form of disability in the world [1]. More than 350 million people are affected by depression worldwide [2]. A lifetime prevalence study of 38,000 people in 10 countries identified proportions varying between 1.5-19.0\% [3]. The highest depression proportions are found in the Middle East, North Africa, sub-Saharan Africa, Eastern Europe and the Caribbean. The lowest proportions were in East Asia, followed by Australia/New Zealand and Southeast Asia, especially in Japan [4]. In Africa the point prevalence also displayed high proportions: $22.6 \%$ for women and $14.3 \%$

\footnotetext{
* Correspondence: mehmet.cakici@neu.edu.tr

'Department of Psychology, Near East University, Arts and Science Faculty,

Lefkosa-Kibris, Mersin 10, Turkey

Full list of author information is available at the end of the article
}

for men [5]. The prevalence of major depressive disorders in Western European countries meanwhile is around 5\% [6]. Interestingly though, in neighbouring countries high prevalence is evident. Clinical frequency for depression in Turkey is $10 \%$ while point prevalence is $13-20 \%$ [7]. In research applied in the south part of Cyprus among Greek Cypriots, the point prevalence of depression was found to be $27.9 \%$ amongst 1500 college students [8].

According to previous studies, one of the main possible risk factors for depression is genetic features which cause functional and structural changes in the brain [9]. Consequently, children whose family members have suffered depression have a higher proportion of major depression. [10]. Silberg, Maes and Eaves (2010) used an expansive twin sample to determine the genetic and environmental correlates of parental and childhood depression [11]. In much research throughout the world, being 
female increases the risk of depression when compared with males $[12,13]$. Another factor which influences depression is marital status. While depression can be observed more frequently in widowed and divorced people, it is less likely to seen in married people $[14,15]$. The risk of developing depression is higher for people who are above the age 55 at which point thoughts of death and medical problems increase $[16,17]$. Onsets of major attacks of depression are also related to stressful life events [18]. Traumatic events such as shock caused by the death of a loved one, serious illness, or domestic violence can all increase the tendency to depression [19, 20]. Further, it has also been identified that social environment and financial problems are other possible risk factors for depression [21].

This study is the first household survey study conducted to find out the prevalence and possible risk factors of major depression in North Cyprus (NC). North Cyprus population has a history of war, migration, economic hardship and traumatic events. The presence of the Major Depression and the risk factors that increase the likelihood of occurrence may be as diverse as the similarities between the populations. Besides the basic risk factors effecting depression, socio-cultural factors involve additional risks affecting the level of prevalence. Differences in sociocultural structure may bear additional risk factors as well as they can influence and cause differentiation of basic risk factors from community to community. Determining the socio-cultural structure and common characteristics in some specific regions of the world, such as the NC, will enable the risk factors of depression to be studied in a wider perspective and to become more aware of the sociocultural characteristics. Although there has been growing curiosity regarding depression and its effects on the NC population limited reliable information is available regarding Major Depression. Hence, the main aims of this study are to provide a scientific analysis of the possible risk factors of depression in $\mathrm{NC}$, and to provide a characterization of all the dimensions of major depression that emerge from the study.

\section{Methods}

\section{Sampling}

The population of the study is Turkish-speaking individuals between 18 and 88 years of age living in North Cyprus. A multi-stage stratified (randomized) quota was used to achieve a representative sample of the adult population in the survey, and 994 people were selected for household interview. The sample size was calculated by sampling formula of known population $(\mathrm{n}=\mathrm{Nt} 2 \mathrm{pq} / \mathrm{d} 2$ $(\mathrm{N}-1)+\mathrm{t} 2 \mathrm{pq})$ [22] where $\mathrm{n}$ was the sample size; $\mathrm{N}$ was the Population size; and $t$ was the value for selected alpha level of 0.025 in each tail $=2.58$ (the alpha level indicates the level of risk the researcher is willing to take that true margin of error that may exceed the acceptable margin of error). Besides, (p)(q) was the estimate of variance which was 0.25 (maximum possible proportion 0.5 ) * 1 (maximum possible proportion 0.5) which produce maximum possible sample size. Finally, d was the acceptable margin of error for proportion being estimated at 0.05 (error a researcher is willing to accept).The selected participants were tabulated according to gender (male/female), age (18-19, 20-29, 30-39, 40-49, 50-65, 65 and above) and geographical region (village/city). The statistics considered for sampling were based on the national census of 4 December, 2011 [23]. With the guidance of the census, five main regions, namely, Nicosia, Famagusta, Kyrenia, Morfou, and İskele, were examined in terms of the main characteristics of their populations. According to the census data, gender, age and region were divided in to quotas which are arranged according to the general population statistics. The stratification of region, gender, age and quarters/villages/cities were arranged by using the proportionate stratification method as the number of the participants in each region were determined by the census 2011. These five central areas are divided into quarters in the rural area and villages in the urban area. 16 quarters, 17 villages and 5 cities were considered randomly in the study.

\section{Fieldwork}

The fieldwork was conducted from April to June 2016. Starting points were randomly selected in particular streets for cities, and in village centers (coffee houses and village mosques) with directions to the north, south, east and west established for the villages. Interviewers tried to draw squares in their movements, starting with the lowest house numbers. One house in three was added to study with the interviewers taking the first right turning each case in order to complete the square. After one square had been completed, a new start point was defined and the creation of a new square commenced. Gender and age quotas were considered in every house entered. Each pollster considered these quotas in every house. If no one was at house or when participants did not give consent, pollsters continued with the next house. Only one person was added to the study in each house, alternating between men and women. If there was more than one candidate in a home, the one whose birthday was closest was selected. Most recent birthday method allows all household members to have an equal chance of selection under the assumption that births are random [24]. The term "nearest birthday" is referred to the day and month not the year of the birth. As there were age quotas in every region this procedure does not affect dispersion. Households were taken by a random selection method but one adult was taken according to nearest birthday if there is more 
than one appropriate person according to quotas. Using such a method enables the pollsters to follow up the same procedure. In this study, all participants were not selected on the birthday basis. The nearest birthday was only selected if there were two or more people in the same age group or in the same sex group in a household. It was also aimed to reduce the systematic bias since it is not known how many people will live in each house and how many people will live in the house. 40 interviewers were used, after training about the questionnaire and the interview process. Each interviewer administered 25 questionnaires. In this way, it was hoped to minimize the margin of error that might result from variation in interviewer application. After detailed information was given to the participants, they were asked to sign a consent form signaling their agreement to participate in the study.

\section{Survey form}

A socio-demographic data form consisting of 21 questions was used to collect profile data and the Turkish version of the Beck Depression Inventory (BDI) was used. BDI was first introduced in 1961 by Beck, Ward, Mendelson, Mock and Erbaugh [25], and subsequently underwent revisions in 1978 (BDI-IA) and 1996 (BDI-II) [26].

\section{Beck depression inventory}

The original BDI form consists of 21 questions. Each item is associated with a behavioral characteristic of depression. The 4-degree scale that accompanies the selfevaluation ranges responses from 0 (no symptoms) to 3 (symptoms highly observed) in terms of emotional, cognitive and motivational symptoms in depression [27]. The internal consistency of work in 1978 showed that two BDI forms were equivalently reliable BDI observes emotional, cognitive and motivational symptoms in depression [25]. The Turkish version of BDI also consists of 21 questions. The total score range is between 0 and 63 , and the cut-off point is 17 , which shows clinical depression A cutoff score of 17 yielded a sensitivity of 50\% and specificity of $92 \%$. The Turkish version of the BDI has been validated. In the sample of Turkish validation study of BDI $(n=108)$, the Cronbach's alpha coefficient was calculated as .91 [26].

\section{Ethical considerations}

The study was approved by the Social and Science Institute Ethical Board at the Near East University of NC and was conducted according to the ethical standards laid down in the 1964 Declaration of Helsinki and its later amendments. Written informed consent from all participants was also obtained.

\section{Data analysis}

In this study, probability weight was used as specifying the sampling design. The probability weight is calculated as $\mathrm{N} / \mathrm{n}$, where $\mathrm{N}=$ the number of elements in the population and $\mathrm{n}=$ the number of elements in the sample. After corrections have been made on the data, all calculations in the study have been made according to sampling weight. In the statistical analyses, Chi-square $(\times 2)$ analysis was used to compare different sociodemographic characteristics of depressive $(\mathrm{BDI} \geq 17)$ and nondepressive $(\mathrm{BDI}<17)$ participant groups. Statistical significance was defined as $p<0.05$. Multivariate logistic regression was also used to explore the relation between depression and possible risk factors. SPSS version 23.0 was used for analysis. In the regression model mean scores of demographic variables which have a statistical meaningful difference after the Pearson Chi-square analysis between the depressive and non-depressive participants were included.

\section{Results}

There were 994 participants in the study, but 978 (98\%) of the forms were used for statistical analysis as $16(2 \%)$ of them had inconsistent or inconclusive answers. 9 of these forms that are considered as invalid were belonged to female participants and 7 of them were belonged to male participants. 465 (47.4\%) of the participants were.

female and $515(52.6 \%)$ male. When the 2011 census was examined, it was found that female $(47.4 \%)$ and male (52.6\%) proportions were similar to the present study. The mean age of the participants with depression was $39.60 \pm$ 16.55 , and $39.23 \pm 14.81$ for the ones without depression $(t=-0.324, p=0.746)$. The distribution of the birthplace of the participants was 479 (48.8\%) in Cyprus, 449 (45.8\%) in Turkey, $13(1.3 \%)$ in the UK and $40(4.1 \%)$ in other countries. With regard to education, 50 (5.1\%) were primary school graduates, 146 participants (14.9\%) were elementary school graduates, 134 (13.7\%) secondary school graduates, 276 (28.1\%) high school graduates and 374 (38.2\%) university graduates. With regard to marital status, 523 (53.4\%) participants were married, 260 (26.5\%) single, 64 (6.5\%) in relationships, $54(5.5 \%)$ widowed, 46 (4.7\%) engaged and 29 (3.0\%) divorced. 581 (59.3\%) of the participants lived in urban areas, 256 (26.1\%) in rural areas and $143(14.6 \%)$ lived in towns.

In terms of the outcomes, 230 (23.5\%) of the participants met the criteria for depression, as opposed to 748 (76.5\%) did not. Women had a significantly higher rate of depression compared to men. Participants in the 1829 age groups and in the 50 years and older age group had a significantly higher ratio of depression than the 30-49 age groups. Participants, who were divorced, widowed, engaged or in a relationship had higher depression rates than married and single participants. 
Participants who were graduates of elementary schools or below had higher rates of depression than participants who were graduates of secondary schools or above. Participants who lived alone had higher rates of depression than those living with a spouse/ partner/ mother/ father/ siblings. Unemployed participants had a higher depression rate than those in employment. It was found that as the monthly income level of the participants decreased, the proportion of depression increased. The highest proportion of depression was found among participants who had no income or were on the minimum wage (1700 Turkish Liras). Participants with physical illnesses had higher depression rates than those without any illness. Participants who used psychoactive drugs also had higher rates of depression, but there was no significant difference for depression rate according to use of alcohol or cigarettes (Table 1 ).

The proportions of depression with regard to occupation were as follows: housewives (42.1\%), unemployed (33.3\%), students $(30.8 \%)$, freelance $(24.3 \%)$, civil servants (19.4\%), workers (19.5\%) and business owners (14.0\%) $(\times 2$ $=46.679, p=0.000)$. Participants who had 4 or more children had higher depression proportions (41.1\%) than those who had $1(16.7 \%)$ or $2-3$ children $(19.3 \%)(\times 2=$ 22.697, $\mathrm{p}=0.000$ ). The number of years the participants had been settled in Cyprus, was found to have no effect on depression rate $(\times 2=11.215, p=0.082)$.

When participants' expectations of a political solution in Cyprus were evaluated, it was discovered that those who want a bi-zonal bi-communal federal state, and those who want a separate republic as a continuation of NC (18.8\%) had lower depression proportions than those desiring a two state confederated state solution (27.1\%), a return to the1960 Cyprus Republic (25.8\%), or union with Turkey (31.8\%). No difference was found between groups according to the ratio of depression in terms of whether their houses are original Greek or original Turkish property $(\times 2=4.083, p=0.130)$, or they own the house or not $(\times 2=6.763, p=0.080)$ (Table 2$)$.

Thus the possible risk factors for depression have been identified as being female, living apart from the family, having an education below high school level, using psychoactive drugs, being unemployed, having an income level less than 3400 Turkish Liras, having a physical disease and wanting a confederated solution in Cyprus (Table 3).

\section{Discussion}

This cross-sectional study found a point prevalence of $23.4 \%$ for relatively high BDI scores $(\geq 17)$ suggesting estimated number of 68.888 people suffering clinical depression among 296.396 people who live in North Cyprus. Being female, a widow, unemployed, having a limited education and low income level, having a physical illness, wanting a confederated solution in Cyprus, living alone, being widowed and using illicit substances were defined as risk factors for depression.

Other international surveys using self-rating scales in community samples have reported prevalence estimates ranging from $11 \%$ to $23 \%$ [28-32]. The wide range of estimates in the prevalence of depressive symptoms may be the result of the diverse methodological approaches, various diagnostic tools used and socio-cultural characteristics of the different target populations [10]. In epidemiological studies, using different cutoff scores in scales of measuring depression may also result in different prevalence estimates for depression [28]. Nonetheless, extremely high prevalence depression proportions have been found in some specific cultures such as Puerto Rico [33], Native Alaskans and Native Americans [34] and Australian Aboriginal people [35]. These cultures share the common characteristics of a history of colonization and related economic exploitation, low education, self-identity problem, a rise in unemployment, increased prevalence of some chronic diseases and dependence on other communities. Extremely high prevalence depression proportions have been also found in such countries as Afghanistan [36], Honduras and the Palestinian territories [6], India [37], Nepal [38], Brazil [39] and Southwest Ethiopia [40]. War and migration histories, economic hardship, a rise in unemployment and socioeconomic problems are the main reasons that increase depression prevalence. These findings, both in specific cultures and countries, show the common macro or environmental reason that increase depression prevalence. When we consider the world prevalence, it is clear that $\mathrm{NC}$ also has one of the higher depression prevalences. The fact that $\mathrm{NC}$ is not a recognized country, is dependent economically and politically on Turkey, recent war (in 1974), migration and British colonial history, previous economic crisis, the uncertainty about the Cyprus Problem, high unemployment rates, and corrupt public order may be seen as the reason for the high depression levels. It has been stated in research that war [41], migration [42], economic crisis [43, 44] and unemployment $[45,46]$ can lead to depression. Previous research conducted in NC also supports these findings. Both North [47] and South Cyprus societies [10] experienced depression as well as PTSD because of war and losing relatives. Ergun et al. (2008) [48] stated that migrants also experienced depression when compared to people who did not migrate as a result of the war. Aktolgalı and Çakıcı (2001) [49] also identified that the economic crisis and bankruptcy of the banks created intense psychological distress and depression, concern about the future and hostility in NC. The deadlock in the Cyprus Problem and future prospects for solution also caused depressive thoughts and emotions [50]. 
Table 1 Demographics of Depressive Participants (BDI $\geq 17)$ and Non-Depressive Participants (BDI < 17) participants in North Cyprus

\begin{tabular}{|c|c|c|c|c|c|}
\hline $\begin{array}{l}\text { Demographic } \\
\text { Variables }\end{array}$ & $\begin{array}{l}\text { Overall sample } \\
\%\end{array}$ & $\begin{array}{l}\text { Depressive Participants } \\
\%\end{array}$ & $\begin{array}{l}\text { Non-Depressive Participants } \\
\%\end{array}$ & $x^{2}$ & $p$ \\
\hline \multicolumn{6}{|l|}{ Gender $(n=978)$} \\
\hline Female & 47.4 & 30.1 & 69.9 & \multirow[t]{2}{*}{20.005} & \multirow[t]{2}{*}{$<0.001^{*}$} \\
\hline Male & 52.6 & 17.9 & 82.1 & & \\
\hline \multicolumn{6}{|l|}{ Age $(n=973)$} \\
\hline $18-29$ & 30.9 & 25.9 & 74.1 & \multirow[t]{3}{*}{3.860} & \multirow[t]{3}{*}{0,145} \\
\hline $30-50$ & 43.4 & 20.4 & 79.6 & & \\
\hline 50 and above & 25.7 & 25.7 & 74.3 & & \\
\hline \multicolumn{6}{|l|}{ Birth Place $(n=978)$} \\
\hline Cyprus & 48.8 & 21.2 & 78.8 & \multirow[t]{4}{*}{4.185} & \multirow[t]{4}{*}{0.242} \\
\hline Turkey & 45.8 & 26.7 & 73.3 & & \\
\hline Britain & 1.3 & 23.1 & 76.9 & & \\
\hline Other & 4.1 & 20.0 & 80.0 & & \\
\hline \multicolumn{6}{|l|}{ Marital Status $(n=978)$} \\
\hline Married & 73.1 & 19.7 & 80.3 & \multirow[t]{4}{*}{20.211} & \multirow[t]{4}{*}{$<0.001^{*}$} \\
\hline Single & 15.3 & 34.5 & 65.5 & & \\
\hline Divorced & 4.1 & 29.6 & 70.4 & & \\
\hline Widow & 7.5 & 40.4 & 59.6 & & \\
\hline \multicolumn{6}{|l|}{ Having Children $(n=870)$} \\
\hline No Children & 40.7 & 24.9 & 75.1 & \multirow[t]{2}{*}{0.843} & \multirow[t]{2}{*}{0.359} \\
\hline Have Children & 59.3 & 22.2 & 77.8 & & \\
\hline \multicolumn{6}{|l|}{ Living Place $(n=977)$} \\
\hline Village & 30.6 & 22.7 & 77.3 & \multirow[t]{2}{*}{0.032} & \multirow[t]{2}{*}{0.857} \\
\hline City & 69.4 & 23.3 & 76.7 & & \\
\hline \multicolumn{6}{|l|}{ Employment Status $(n=977)$} \\
\hline Employed & 59.1 & 17.0 & 83.0 & \multirow[t]{2}{*}{34.271} & \multirow[t]{2}{*}{$<0.001^{*}$} \\
\hline Unemployment & 40.9 & 33.2 & 66.8 & & \\
\hline \multicolumn{6}{|l|}{ Education Level $(n=978)$} \\
\hline Illiterate & 5.1 & 44.0 & 56.0 & \multirow[t]{3}{*}{13.780} & \multirow[t]{3}{*}{$0.001^{*}$} \\
\hline Primary-Secondary School & 28.6 & 25.2 & 74.8 & & \\
\hline High School and above & 66.3 & 21.3 & 78.7 & & \\
\hline \multicolumn{6}{|l|}{ Monthly Income $(n=975)$} \\
\hline $1700 \mathrm{TL}$ and beloved & 34.1 & 32.0 & 68.0 & 20.849 & $<0.001^{*}$ \\
\hline $1701-10,000 \mathrm{TL}$ & 61.7 & 18.8 & 81.2 & & \\
\hline $10,000 \mathrm{TL}$ and more & 4.3 & 26.2 & 73.8 & & \\
\hline Physical IIIness $(n=977)$ & & & & & \\
\hline Have Physical Disease & 9.2 & 36.7 & 63.3 & 9.272 & $0.002^{*}$ \\
\hline Doesn't Have Physical Disease & 90.8 & 22.3 & 77.7 & & \\
\hline Whom Living With $(n=978)$ & & & & & \\
\hline Alone & 13.8 & 33.3 & 66.7 & 19.524 & $<0.001^{*}$ \\
\hline Spouse / Partner / Lover & 53.6 & 19.1 & 80.9 & & \\
\hline Mother / Father / Brother & 18.7 & 22.4 & 77.6 & & \\
\hline Other & 13.9 & 32.8 & 67.2 & & \\
\hline
\end{tabular}

Alcohol Use $(n=976)$ 
Table 1 Demographics of Depressive Participants (BDI $\geq 17)$ and Non-Depressive Participants (BDI < 17) participants in North Cyprus (Continued)

\begin{tabular}{|c|c|c|c|c|c|}
\hline $\begin{array}{l}\text { Demographic } \\
\text { Variables }\end{array}$ & $\begin{array}{l}\text { Overall sample } \\
\%\end{array}$ & $\begin{array}{l}\text { Depressive Participants } \\
\%\end{array}$ & $\begin{array}{l}\text { Non-Depressive Participants } \\
\%\end{array}$ & $x^{2}$ & $p$ \\
\hline Non-user & 23.2 & 24.0 & 76.0 & 2.536 & 0.281 \\
\hline 1-40 times & 28.3 & 26.5 & 73.5 & & \\
\hline 40 times and above & 48.6 & 21.5 & 78.5 & & \\
\hline \multicolumn{6}{|l|}{ Smoking $(n=976)$} \\
\hline Non-user & 30.7 & 21.5 & 78.5 & 1.177 & 0.555 \\
\hline 1-40 times & 15.6 & 25.0 & 75.0 & & \\
\hline 40 times and above & 53.8 & 24.6 & 75.4 & & \\
\hline \multicolumn{6}{|l|}{ Drug Use $(n=978)$} \\
\hline User & 30.4 & 26.0 & 74.0 & 6.672 & $0.010^{*}$ \\
\hline Non-user & 69.6 & 18.3 & 81.7 & & \\
\hline
\end{tabular}

${ }^{*} \mathrm{p}<0.05$ significant level

In some studies, racial/ ethnic minorities have been found to suffer from higher prevalence of depression [34, 35]. Other studies however have found similar [40] or even lower prevalence [51] among racial/ethnic minorities. The US Department of Health and Human Services (2001) reported that some minority groups have common possible risk factors for mental illness resulting from the fact that these populations often experience social and economic inequality, exposure to racism and discrimination, increased prevalence of some chronic diseases, and less access to care and treatment for mental and physical health conditions [52]. This study showed that a similar depression prevalence proportion is evident among both native Turkish Cypriots and immigrants from Turkey. Since immigration has mainly taken place post-partition of the island between Greek Cypriots and Turkish Cypriots in 1974, there has been a substantial migration of Turkish people to North Cyprus. As a former British colony, many Turkish Cypriots also immigrated to the UK, as well as to other Common wealth destinations including Australia, South Africa and Canada, as well as The United States. Consequently, the number of immigrants from Turkey has outgrown the number of Turkish Cypriots [53]. After a 40 year period of migration from Turkey, the native Turkish Cypriot population has decreased to about

Table 2 Ideas about Cyprus Political Solution and Status of Home lived of Depressive Participants (BDI $\geq 17)$ and Non-Depressive participants $\left(B D I^{<} 17\right)$ in North Cyprus

\begin{tabular}{|c|c|c|c|c|}
\hline $\begin{array}{l}\text { Demographic } \\
\text { Variables }\end{array}$ & $\begin{array}{l}\text { Depressive Participants } \\
\%\end{array}$ & $\begin{array}{l}\text { Non-Depressive Participants } \\
\%\end{array}$ & $x^{2}$ & $\mathrm{p}$ \\
\hline \multicolumn{5}{|l|}{ Own Resources $(n=977)$} \\
\hline Owned & 21.5 & 78.5 & 6.763 & 0.080 \\
\hline Government Owned & 33.9 & 66.1 & & \\
\hline On Rent & 26.9 & 73.1 & & \\
\hline Other & 20.7 & 79.3 & & \\
\hline \multicolumn{5}{|l|}{ Status of Home Lived $(n=971)$} \\
\hline Turkish Property & 24.6 & 75.4 & 4.083 & 0.130 \\
\hline Greek Property (Allocated) & 25.8 & 74.2 & & \\
\hline Greek Property (Equivalent) & 17.8 & 82.2 & & \\
\hline \multicolumn{5}{|c|}{ Ideas about Cyprus Political Solution $(n=978)$} \\
\hline New Federal state & 18.8 & 81.2 & 18.865 & $0.002^{*}$ \\
\hline Con-federal states & 27.1 & 72.9 & & \\
\hline Continuation of Status & 18.0 & 82.0 & & \\
\hline Unite to Turkey & 32.0 & 68.0 & & \\
\hline $\begin{array}{l}\text { Forming again } 1960 \text { Republic of } \\
\text { Cyprus }\end{array}$ & 25.8 & 74.2 & & \\
\hline
\end{tabular}


Table 3 Odss Ratio and Confidence Intervals of some demographic variables obtaining from Multivariate Logistic regression

\begin{tabular}{lll}
\hline Demographic variables & \multicolumn{2}{l}{ Depressive / Non-Depressive Participants } \\
\cline { 2 - 3 } & Odss Ratio & $95 \% \mathrm{Cl}$ \\
\hline Gender (Female / Male) & 1.422 & $(1.199-1.687)^{* *}$ \\
Living status (not with family / with family) & 1.724 & $(1.252-2.374)^{* *}$ \\
Education (High school below / above) & 1.438 & $(1.059-1.952)^{*}$ \\
Drugs (user / not user) & 1.382 & $(1.070-1.784)^{*}$ \\
Marital Status (single / married) & 1.601 & $(1.190-2.155)^{*}$ \\
Employment Status (unemployed / employed) & 2.425 & $(1.795-3.276)^{* *}$ \\
Monthly Income (3400 TL below / above) & 1.602 & $(1.212-2.118)^{* *}$ \\
Physical Disease (having/don't having) & 1.686 & $(1.251-2.271)^{* *}$ \\
Solution in TRNC (willing con-federal/federal) & 1.424 & $(1.030-1.970) *$
\end{tabular}

${ }^{*} p \leq 0.05$

${ }^{* *} \mathrm{p} \leq 0.001$ significant level, $\mathrm{Cl}=$ Confidence Interval

$115,000-85,000$ and the Turkish migrant population increased to 130,000-160,000. The social, economic and political relations between native Turkish Cypriots and immigrants from Turkey are strained, with Turkish Cypriots expressing the feeling that they have been colonized and invaded culturally [54]. Experiences of acculturation, changes in sociocultural norms and loss of social or economic status can all be considered reasons for the development of mental health problems $[55,56]$. It is also observed however that not every mental health process is influenced by acculturation processes in the same way. While pathological gambling is found to be more common among native Turkish Cypriots than the immigrants from Turkey [57], illicit drug use is more common among immigrants from Turkey [58]. When cultural attitudes of both groups are observed, acculturation strategies of separation chosen by native Turkish Cypriots, and assimilation chosen by immigrants from Turkey were found to be the reasons for high proportions of drug use among immigrants from Turkey [59] and problem and pathologic gambling proportions among native Turkish Cypriots [60]. Hence minority characteristics may impact on certain mental disorder processes, whilst being an immigrant may be the origin of others. Community behavioral reactions that result in different mental disorder prevalences thus depend on each culture's own unique socio-cultural context and acculturation configurations. In line with this, despite the shared risk factors, there are psychosocial factors that uniquely confer risk to one class of disorders over the other [61]. In other studies of depression also, significant differences have been demonstrated across cultures in the experience, expression and consequences of a range of emotional terms and illnesses [62].

When political views are considered, people who would like to unite with Turkey, support confederation, and want to reform the 1960 Republic of Cyprus again exhibit significantly higher prevalence of depression compared to people who are pleased with the current unrecognized government "Turkish Republic of Northern Cyprus" and people who believe in forming a new government with bi-zonal bi-communal federal states. Political beliefs and housing status are related with the previous war and migration events of the participants living in the NC. The negotiation, which has been ongoing for 40 years between the Turkish Cypriots and the Greek Cypriots in the NC today, causes continuing uncertainty about the future which in turn has an impact on depression. The results of this study show that the Cyprus problem negotiations that have been continuing for some 40 years under the auspices of The United $\mathrm{Na}$ tions with a view to establishing a united federal government of Cyprus may disappoint people those who believe in a con-federal system, union with Turkey, or a return to the 1960 Republic. Furthermore, the ambiguity of the Cyprus problem, has entrenched the status quo. Studies which focus on the relationship between stress and depression have shown that sociopolitical reasons can be underlying factors in the development of depression [63, 64]. Studies have also shown that depression is also elevated during and after events such as war, prolonged socio-political conflict and political turmoil in low-income countries $[65,66]$.

According to the research data, the depression prevalence in women is higher than in men. This is consistent with previous research suggesting that depression is more common in women than men [67-72]. However, not all research supports this finding. Studies of people who experienced war in Syria [40] and of a student group who did not graduate in Sri Lanka [73, 74] showed no significant difference between male and female depression prevalence proportions. The higher prevalence of depression levels in women is thus not fully explained. In research carried out so far, it has been found that depression may be caused by women's 
hormonal changes. Also, postpartum and premenstrual periods can cause to depression [75].

Even though age groups were not statistically different, the depression prevalence amongst the youth and elderly was higher compared with middle age. Studies suggest that point prevalence in youth and elderly is much higher [10, 76, 77]. The higher prevalence of depression in the elderly can be explained by biological changes, medical problems and older people's diminished mental activity [78]. On the other hand, hormonal changes [79], low self-esteem [80], and the need to belong [81] may explain the higher prevalence in youth.

When marital status was examined, it was discovered that married people have lower depression prevalence then divorced and widowed. However, Yan's study in China stated that being married and over 55 of age is a risk factor compared to being divorced or widowed [19]. Being divorced or widowed is a phenomenon influenced by cultural norms [82]. Divorced people usually plan to re-marry, but only some of them do. In NC, divorce is seen as unacceptable by some, especially for women. All these findings show that marital status may have different effects on depression in different cultures. Although studies among Turkish societies in Turkey $[83,84]$ show a relation between having children and depression level, this was not the case in this present study because of the family structure in NC. Due to the fact that, Turkish Cypriot family structure is an extensive family structure which is crowded and supportive. This kind of a family structure decreases the responsibilities of raising a child as it enables to receive support and share the responsibilities of the children with other family members.

In this study, as with other similar research, individuals living alone $[74,85,86]$, unemployed $[87,88]$, with a low educational level [70,89], lower incomes [78, 90, 91], or physical illness [70, 90, 92] have higher depression prevalence. Smoking and use of alcohol are not considered as risk factors in the development of depression in NC. Although this finding is also supported by some research [93-95], other studies have found that smoking and alcohol use do indeed have a direct correlation with depression [40,67-73]. However the depression prevalence in illicit psychoactive substance users compared with non-users is higher. Illicit psychoactive substance use is known to lead to depression [40, 93].

\section{Limitations}

First, the BDI scale, like other self-reporting screening instruments, is not perfect in measuring clinical depression; it is mainly used to assess symptom severity rather than as a diagnostic tool [96]. Second, it is impossible to as certain temporality in cross-sectional studies. For example, having economic problems can lead to depression, but depression can also lead to economic problems. Third, non-response bias may cause underestimation of the levels of depressive symptoms, because people who participate in this kind of health surveys are healthier than those who do not [97]. Fourth, some populations are not included in the samples such as those in prisons, dormitories, hospitals or the army.

\section{Conclusion}

Extremely high prevalence of clinical depression was observed among North Cyprus Population. Being women, living alone, low level of education, being widowed, using drugs are found to be main possible risk factors for depression. In regions like $\mathrm{NC}$, further research with long-term follow-up is needed to increase our understanding of the possible risk factors for extremely high depression prevalence at-risk populations. Each culture or country has unique characteristics specific to itself, besides individual factors socio-cultural features like socioeconomic problems, high unemployment, war, migration and colonization history, prevalence of some chronic diseases and dependence on another country may lead to an increase in the prevalence of depression. North Cyprus Population is faced with many struggles throughout their lives relative to their historical, cultural, and social structural position in Cyprus. Because of these issues heighten NC population's vulnerability for depressive symptoms, depression must be prior public mental healthcare in NC. It is useful for researchers and policy makers to understand the socio-cultural factors as well as the individual factors behind depression as they seek to evaluate and improve mental health program policy in NC. The prevalence of depressive disorders should be monitored by NC Health Ministry and Public Health Department through constant surveillance, and socio-cultural characteristics also should be considered when planning and implementing interventions. The understanding of the social atmosphere that surrounds the major depressive patients is the focus of consideration of the patients together with socio-cultural factors, not just physical symptoms. Socio-cultural factors are important in the development of major depressive disorder and the evaluation of social factors such as stress, lifestyle, income, unemployment and deprivation will have a positive impact on the recovery process. Understanding of the relationship between sociocultural factors and major depression, positive changes in social and economic fields as well as individual therapies, and preventive public health policies related to these issues will reduce the prevalence of major depression.

\section{Additional file}

Additional file 1: Weight total - depression-prevalence dataset. (XLSX 258 kb)

\section{Abbreviations}

BDI: Beck Depression Inventory; NC: North Cyprus; SPSS: Statistical Package for the Social Sciences; US: United States 


\section{Acknowledgments}

We would like to acknowledge the Near East University psychology students who contributed to the collection of the data.

\section{Funding}

Not applicable.

\section{Availability of data and materials}

Raw dataset generated or analyzed during this study are included in this published article (Additional file 1).

\section{Authors' contributions}

Each author made substantive contribution towards the development of this paper. MC is the major investigator for this study, conceptualized the topic of study, coordinated all the data collection, and made substantive contribution in the drafting and writing up of the paper. OG is also a investigator of the study and made strong support in writing up this paper. $A B$, supported data collection, designing the study tools, training of the pollsters and participated in writing up the paper. EB did all the statistical analysis and made contributions in writing up the paper. AE thoroughly reviewed the final draft and is responsible for the last version. All authors read and approved the final manuscript.

\section{Authors' information}

1MC: MD PhD, is Professor of Psychiatry in Nicosia Psychiatry Centre, Cyprus Mental Health Institute, Head of the Department of Psychology, Faculty of Arts and Sciences, Near East University. 20G: MSc, Department of Psychology, Faculty of Arts and Sciences, Near East University. 3AB: MSc, is psychologist in Nicosia Psychiatry Centre, Cyprus Mental Health Institute, Department of Psychology, Faculty of Arts and Sciences, Near East University. 4 EB: MD PhD, in Nicosia Psychiatry Centre, Cyprus Mental Health Institute, Head of the Department of Psychology, Faculty of Arts and Sciences, Near East University. 4AE: PhD, in Nicosia Psychiatry Centre, Cyprus Mental Health Institute, Faculty of Education, Department of Psychological Counseling and Guidance, Near East University.

\section{Ethics approval and consent to participate}

The study was approved by the Social and Science Institute Ethical Board at the Near East University of NC and was conducted according to the ethical standards laid down in the 1964 Declaration of Helsinki and its later amendments. Written informed consent from all participants was also obtained.

\section{Consent for publication}

Not applicable.

\section{Competing interests}

The authors declare that they have no competing interests.

\section{Publisher's Note}

Springer Nature remains neutral with regard to jurisdictional claims in published maps and institutional affiliations.

\section{Author details}

'Department of Psychology, Near East University, Arts and Science Faculty, Lefkosa-Kibris, Mersin 10, Turkey. ${ }^{2}$ Department of Psychological Counselling and Guidance, Near East University, Faculty of Education, Lefkosa-Kibris, Mersin 10, Turkey.

Received: 30 December 2016 Accepted: 20 November 2017 Published online: 04 December 2017

\section{References}

1. Murray CJ, Lopez AD. Evidence-based health policy lessons from the global burden of disease study. Science. 1996;274(5288):740-3.

2. WHO. Depression. 2016. http://apps.who.int/mediacentre/factsheets/fs369/ en/index.html Accessed 13 August 2016.

3. Weissman MM, Bland RC, Canino GJ, Faravelli C, Greenwald S, Hwu HG, Joyce PR, Karam EG, Lee CK, Lellouch J, Lepine JP, Newman SC, Rubio M, Wells JE,

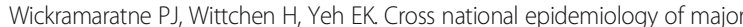
depression and bipolar disorder. JAMA. 1996;276(4):293-9.
4. Ferrari AJ, Charlson FJ, Norman RE, Patten SB, Freedman G, Murray CJ, Whiteford $\mathrm{H}$. Burden of depressive disorders by country, sex, age, and year: findings from the global burden of disease study 2010. PLoS Med. 2013; 10(11):1-12.

5. Orley J, Wing JK. Psychiatric disorders in two African villages. Arch Gen Psychiatr. 1979;36:513-20.

6. Paykel ES, Brugha T, Fryers T. Size and burden of depressive disorders in Europe. Eur Neuropsychopharmocol. 2005;15:411-23.

7. Doğan O. Türkiye'de psikiyatrik epidemiyoloji çalışmalarında özgün bir örnek: sivas'ta yapılan araştırmaların önemli bulguları (as an example of a research among specific group in epidemiological studies in Turkey: important findings of epidemiological studies in Sivas). Bulletin of Turkish Psyhiatry Organization (Turkish). 2010;13(1):12-22.

8. Sokratous S, Merkouris A, Middleton N, Karanikola M. The prevalence and socio-demographic correlates of depressive symptoms among Cypriot university students: a cross-sectional descriptive co-relational study. BMC Psychiatry. 2014;14:235

9. Akif CM. MicroRNAs as a new hope for depression. Journal of Mood Disorders. 2015:5(1):23-30.

10. Hammen C, Burge D, Burney E. Longitudinal study of diagnoses in children of women with unipolar and bipolar affective disorder. Arch Gen Psychiatr. 1990;47:1112-7.

11. Silberg $J$, Maes $H$, Eaves $L J$. Genetic and environmental influences on the transmission of parental depression to children's depression and conduct disturbance: an extended children of twins study. J Child Psychol Psyc. 2010;51(6):734-44.

12. Cole MG, Dendukuri N. Risk factors for depression among elderly community subjects: a systematic review and meta-analysis. Am J Psychiat. 2003;160:1147-56

13. Patten SB, Williams JVA, Lavorato DH, Wang JL, Bulloch AGM, Sajobi T. The association between major depression prevalence and sex becomes weaker with age. Soc Psych Psych Epid. 2016;51:203-10.

14. Coryell W, Endicott J, Keller M. Major depression in a nonclinical sample. Demographic and clinical risk factors for first onset. Arch Gen Psychiatr. 1992;49(2):117-25

15. Parker G, Hadzi Pavlovic D, Greenwald S, Weissman M. Low parental care as a risk factor to lifetime depression in a community sample. J Affect Disorders. 1995;33(3):173-80.

16. Klonoff EA, Landrine $H$. Depressive symptoms and smoking among US black adults: absence of a relationship. J Health Psychol. 2001;6:645-9.

17. Yan XY, Huang SM, Huang CQ, Wu WH, Qın Y. Marital status and risk for late life depression: a meta-analysis of the published literature. J Int Med Res. 2011:39:1142-54.

18. Kendler KS, Karkowski LM, Prescott CA. Causal relationship between stressful life events and the onset of major depression. Am J Psychiat. 1999:156:837-41.

19. Person C, Tracy M, Galea S. Risk factors for depression after a disaster. J Nerv Ment Dis. 2006:194(9):659-66.

20. Rao D, Kumar S, Mohanraj R, Frey S, Manhart LE, Kaysen DL. The impact of domestic violence and depressive symptoms on preterm birth in South India. Soc Psych Psych Epid. 2016;51:225-32. https://doi.org/10.1007/s00127015-1167-2.

21. Murphy JM, Olivier DC, Monson RR, Sobol AM, Federman EB, Leighton AH. Depression and anxiety in relation to social status. A prospective epidemiologic study. Arch Gen Psychiatr. 1991;48(3):223-9.

22. Yazicioglu Y, Erdoga S. SPSS applied scientific research methods. Ankara: Detail Publishing; 2004

23. Census of Population. Social and economic characteristics of population, December 4, 2011. State Institute of Statistics, Printing Division, North Cyprus; 2011

24. Salmon C, Nichols J. The next-birthday method of respondent selection. Public Opinion Quarterly. 1983:47(2):270-6. https://doi.org/10.1086/268785.

25. Beck AT, Ward CH, Mendelson M, Mock J, Erbaugh J. An inventory for measuring depression. Arch Gen Psychiatr. 1961;4(6):561-71. https://doi.org/ 10.1001/archpsyc.961.01710120031004.

26. Beck AT, Steer RA, Ball R, Ranieri W. Comparison of Beck Depression Inventories -IA and -II in psychiatric outpatients. J Pers Assess. 1996;67(3):588-97.

27. Hisli N. A study on the validity of Beck Depression Scale. Turkish Journal of Psychology. 1988:6(22):118-26.

28. Leiderman EA, Lolich M, Vázquez GH, Baldessarini RJ. Depression: Pointprevalence and sociodemographic correlates in a Buenos Aires community sample. J Affect Disorders. 2012;136(3):1154-8. 
29. Oliver JM, Simmons ME. Depression as measured by the DSM-III and the Beck Depression Inventory in an unselected adult population. J Consult Clin Psych. 1984;52:892-8.

30. lancu I, Lepkifker E, Drory Y. An epidemiological study of depressive symptomatology among Israeli adults: prevalence of depressive symptoms and demographic risk factors. Israel J Psychiat. 2003;40(2):82-9.

31. Alouja A, Leinsalu M, Shlik J, Vasar V, Luuk K. Symptoms of depression in the Estonian population: prevalence, sociodemographic correlates and social adjustment. J Affect Disorders. 2004;78:27-35.

32. Bobak M, Pikhart H, Pajak A, Kubinova R, Malyutina S, Sebakova H, ToporMadry R, Nikitin Y, Marmot M. Depressive symptoms in urban population samples in Russia, Poland and the Czech Republic. Brit J Psychiat. 2006;188: 359-65.

33. Centers for Disease Control and Prevention. Current depression among adults. Errata. 2010;60(16):518

34. Xu JQ, Kochanek KD, Murphy SL, Tejada-Vera B. Deaths: Final data for 2007. National vital statistics reports; National Center for Health Statistics, Hyattsville, Maryland. 2010;58:19.

35. Brown A, Mentha R, Howard M, Rowley K, Reilly R, Paquet C, O'Dea K. Men, hearts and minds: developing and piloting culturally specific psychometric tools assessing psychosocial stress and depression in central Australian Aboriginal men. Soc Psych Psych Epid. 2016;51:211-23.

36. Cardozo BL, Bilukha OO, Crawford CA, Shaikh I, Wolfe MI, Gerber ML, Anderson M. Mental health, social functioning, and disability in postwar Afghanistan. JAMA. 2004;292:575-84.

37. Shidhaye R, Gangale S, Patel V. Prevalence and treatment coverage for depression: a population-based survey in Vidarbha, India. Soc Psychiatry Psychiatr Epid. 2016;51:993-1003.

38. Thapa SB, Hauff E. Psychological distress among displaced persons during an armed conflict in Nepal. Soc Psychiatry Psychiatr Epid. 2005;40:672-9.

39. Kessler RC, Birnbaum HG, Shahly V, Bromet E, Hwang I, et al. Age differences in the prevalence and co-morbidity of DSM-IV major depressive episodes: results from the WHO World Mental Health Survey Initiative. Depress Anxiety. 2010;27(4):351-64.

40. Mossie A, Kindu D, Negas A. Prevalence and severity of depression and its association with substance Use in Jimma Town, Southwest Ethiopia. Depress Res Treat. 2016; doi:10.1155/2016/3460462.

41. Naja WJ, Aoun MP, El Khoury EL, Bou Abdallah FJ, Ramzi HS. Prevalence of depression in Syrian refugees and the influence of religiosity. Compr Psychiat. 2016;68:78-85.

42. Aker T, Ayata B, Özeren M, Buran B, Bay A. Forced internally displacement: Psychosocial consequences. Anatolian Journal of Psychiatry. 2002;3(2):97103.

43. Economou M, Madianos M, Peppou LE, Patelakis A, Stefanis CN. Major depression in the Era of economic crisis: A replication of across-sectional study across Greece. J Affect Disorders. 2013;145(3):308-14.

44. Buffel V, Velde SV, Bracke P. The mental health consequences of the economic crisis in Europe among the employed, the unemployed, and the non-employed. Soc Sci Res. 2015;54:263-88.

45. Topuzoğlu A, Binbay T, Ulaş H, Elbi H, Tanık FA, Zağlı N, Alptekin K. The epidemiology of major depressive disorder and subthreshold depression in Izmir, Turkey: Prevalence, socio economic differences, impairment and helpseeking. J Affect Disorders. 2015;181:78-86.

46. Najafipour H, Banivaheb G, Sabahi A, Naderi N, Nasirian M, Mirzazadeh A. Prevalence of anxiety and depression symptoms and their relationship with other coronary artery disease risk factors: A population-based study on 5900 residents in Southeast Iran. Asian Journal of Psychiatry. 2016;20:55-60.

47. Şimşek AH. Post-traumatic Stress Disorder Among Turkish Cypriot Fighters of Erenköy Exclave Battle. Dissertation, Near East University Graduate School of Social Sciences, North Cyprus; 2015.

48. Ergün D, Çakıcı M, Çakıcı E. Comparing psychological responses of internally displaced and non-displaced Turkish Cypriots. Torture. 2008;18(1):20-8.

49. Aktolgalı M, Çakıcı M. Investigating psychologic and psychopathologic symptoms among bunkrupters in North Cyprus. 8.Turkish Social Psychiatry Congress Abstarct Book, North Cyprus. 2001;228

50. Çakı I E. Transgenerational transmission of trauma of internal displacement. Psychodrama thesis, Dr. Abdülkadir Özbek Psychodrama Institute, Ankara, Turkey; 2010.

51. Kessler RC, Berglund P, Demler O, Jin R, Koretz D, Merikangas KR, Walters EE, Wang PS. The epidemiology of major depressive disorder: results from the National Comorbidity Survey Replication (NCS-R). JAMA. 2003;289:3095-105.
52. US Department of Health and Human Services. Mental health: culture, race, and ethnicity: a supplement to mental health: a report of the Surgeon General. Rockville, MD: US Department of Health and Human Services, Office of the Surgeon General, Substance Abuse and Mental Health Services; 2001. Administration. http://www.surgeongeneral.gov/library/ mentalhealth/cre. Accessed 12 Aug 2016.

53. Hatay M. Is the Turkish Cypriot population shrinking? An overview of the ethno-demography of Cyprus in the light of the preliminary results of the 2006 Turkish-Cypriot Census. Oslo (PRIO): International Peace Research Institute, Oslo, Norway; 2007.

54. Navaro-Yashin Y. De-ethnicizing the Ethnography of Cyprus: Political and social conflict between Turkish Cypriots and settlers from Turkey. In Papadakis Y, Peristianis N and Welz G (Ed.). Divided Cyprus: modernity, history, and an island in conflict. Indiana University Press Publications, Bloomington, USA; 2006. p. 84-99.

55. Kramer EJ, Kwong K, Lee E, Chung E. Cultural factors influencing the mental health of Asian Americans. West J Med. 2002;176(4):227-31.

56. Dyall L. Kanohi ki Te Kanohi. Face to face. A Maori face to gambling. New Ethical Journal: New Zealand's Journal of Patient Management. 2002;5(1): $11-16$.

57. Çakıcı M, Çakıcı E, Karaaziz M. Lifetime prevalence and risk factors of problem and pathologic gambling in North Cyprus. J Gambl stud. 2016; 32(1):11-23.

58. Çakıcı M, Tutar N Çakııı E, Karaaziz M, Eş A. The prevalence and risk factors of psychoactive drug use in Turkish Republic of Northern Cyprus. Anatolian Journal of Psychiatry. 2016; doi:10.5455/apd.226191.

59. Bayramoğlu R. Comparison of Cultural and Religion Attitudes Differences of Psychoactive Drug Use Characteristics between Cyprus and Turkey Born University Students. Master Thesis, Near East University, Institute of Social Sciences, North Cyprus; 2016

60. Çakıcı M, Çakıcı E, Karaaziz M. Lifetime prevalence and risk factors of problem and pathologic gambling and relation with cultural attitudes in North Cyprus. 50. Turkish National Psychiatry Congress Abstracts, AntalyaTurkey, Turkish Journal of Psychiatry. 2014;32(Suppl 2):7.

61. Fatori D, Bordin IA, Curto BM, Paula CS. Influence of psychosocial risk factors on the trajectoryof mental health problems from childhood to adolescence: a longitudinal study. BMC Psychiatry. 2013;13:31.

62. Good B, Kleinman A. Epilogue: Culture and Depression. In: Good B, Kleinman A (eds) Culture and depression. Studies in the anthropology and cross-cultural psychiatry of affect and disorder. University of California Press, Berkeley; 1985.

63. Kleinman A. Patients and healers in the context of culture. CA: University of California Press, Berkeley; 1980.

64. Shweder R. Thinking through cultures: Expeditions in cultural psychology. MA: Harvard University Press, Cambridge; 1991.

65. Basoglu M, Livanou M, Crnobaric C, Franciskovic T, Suljic E, Duric D, et al. Psychiatric and cognitive effects of war in former Yugoslavia: Association of lack of redress for trauma and posttraumatic stress reactions. J Am Med Assoc. 2005;294:580-90.

66. Prorokovic A, Cavka M, Cúbela Adoric V. Psychosomatic and depressive symptoms in civilians, refugees, and soldiers: 1993-2004 longitudinal study in Croatia. Croation Medicine. 2005;46:275-81.

67. Canetti D, Galea S, Hall BJ, Johnson RJ, Palmieri PA, Hobfoll SE. Exposure to prolonged socio-political conflict and the risk of PTSD and depression among Palestinians. Psychiatry. 2010;73(3):219-31.

68. Kim MD, Chul S, Lee SY. Prevalence of depression and correlates of depressive symptoms for residents in urban part of Jeju Island. Int J Soc Psycht. 2007;53(2):123-34.

69. Velde SV, Bracke P, Levecque K, Meuleman B. Gender differences in depression in 25 European countries after eliminating measurement bias in the CES-D 8. Soc Sci Res. 2010;39(3):396-404.

70. Santos ER, Huang H, Menezes PR, Scazufca M. Prevalence of depression and depression care for populations registered in primary care in two remote cities in the Brazilian Amazon. Plos One. 2016;11(3):1-13.

71. Tanjanai PT, Moradinazar M, Najafi F. Prevalence of depression and related social and physical factors amongst the Iranian elderly population in 2012 Geriatr Gerontol. 2016; doi:10.1111/ggi.12680.

72. Torre AY, Oliva N, Echevarrieta PL, Pérez BG, Caporusso GB, Titaro AJ, Todaro KA, Cuatz M, Locatelli M, Nelson LM, Mac M, Baldessarini RJ, Daray FM. Major depressionin hospitalized Argentine general medical patients: Prevalence and risk factors. J Affect Disorders. 2016;197:36-42. 
73. Aghakhani N, Nia HS, Eghtedar S, Rahbar N, Jasemi M, Zadeh MM. Prevalence of depression among students of urmia university of medica sciences (Iran). Iran J Psychiatry Behav Sci. 2011;5(2):131-5.

74. Amarasuriya SD, Jorm AF, Reavley NJ. Prevalence of depression and its correlates among undergraduates in Sri Lanka. Asian Journal of Psychiatry. 2015;15:32-7. doi:10.1016/j.ajp.2015.04.012

75. Burt VK, Stein K. Epidemiology of depression throughout the female life cycle. J Clin Psychiat. 2002;63(7):9-15.

76. Papadopoulos FC, Petridou E, Argyropoulou S, Kontaxakis V, Dessypris N, Anastasiou A, Katsiardani KP, Trichopoulos D, Lyketsos C. Prevalence and correlates of depression in late life: a population based study from a rural Greek town. Int J Geriatr Psych. 2005;20:350-7.

77. Liu J, Yan F, Ma X, Guo HL, Tang YL, Rakofsky JJ, Wu XM, Li XQ, Zhu H, Guo XB, Yang Y, Li P, Cao XD, Li HY, Li ZB, Wang P, Xu QY. Prevalence of major depressive disorder and socio-demographic correlates:Results of a representative household epidemiological survey in Beijing, China. J Affect Disorders. 2015;179:74-81.

78. Holvast F, Verhaak PF, Dekker JH, Waal MW, Harm MW, Penninx BW, Comijs $\mathrm{H}$. Determinants of receiving mental health care for depression in older adults. J Affect Disorders. 2012;143:69-74.

79. Angold A, Costello EJ, Erkanli A, Worthman CM. Pubertal changes in hormone levels and depression in girls. Psychol Med. 1999;29:1043-53.

80. Eskin M, Ertekin K, Harlak H, Dereboy Ç. Prevalence of and Factors Related to Depression in High School Students. Turkish Journal of Psychiatry. 2008; 19(4):382-9.

81. Allen JP, Porter MR, McFarland FC. Leaders and followers in adolescent close friendships: susceptibility to peer influence as a predictor of risky behavior friendship instability, and depression. Dev Psychopathol. 2006;18:155-72.

82. Jang S, Kawachi I, Chang J, Boo K, Shin H, Lee H, Cho S. Marital status, gender, and depression: Analysis of the baseline survey of the Korean Longitudinal Study of Ageing. Soc Sci Med. 2009;69(11):1608-15.

83. Renner W, Berry JW. The ineffectiveness of group interventions for female Turkish migrants with recurrent depression. Soc Behav Personal. 2011;39(9): 1217-34.

84. Kayahan B, Altıntoprak E, Karabilgin S, Öztürk Ö. The relationship between risk factors and depression scores, and depression prevalence among women between 15-49 years age. Anatolian Journal of Psychiatry. 2003;4: 208-19.

85. Hidaka BH. Depression as a disease of modernity: Explanations for increasing prevalence. J Affect Disorders. 2012;140:205-14.

86. Bhamani MA, Karim MS, Khan MM. Depression in the elderly in Karachi, Pakistan: a cross sectional study. BMC Psychiatry. 2013;13:181.

87. Vinokur AD, Price RH, Caplan RD. Hard times and hurtful partners: How financial strain affects depression and relationship satisfaction of unemployed persons and their spouses. J Pers Soc Psychol. 1996;71(1):166-79.

88. Melgar N, Máximo R. A cross-country analysis of the risk factors for depression at the micro and macro level. Am J Econ Sociol. 2010;71(2): 354-76.

89. Coelho F, Pinheiro RT, Silva RA, Quevedo L, Souza L, Castelli RD, Matos MB, Pinheiro K. Major depressive disorder during teenage pregnancy: sociodemographic, obstetric and psychosocial correlates. Official Journal of the Brazilian Psychiatric Association. 2013;35(1):51-56.

90. Özdel L, Bostancı M, Özdel O, Oğuzhanoğlu N. The relationship with sociodemographic characteristics and depressive symptoms in university students. Anatolian Journal of Psychiatry 2002;3(3):155-61.

91. Vable AM, Canning D, Glymour MM, Kawachi I, Jimenez MP, Subramanian SV. Can social policy influence socioeconomic disparities? Korean War Gl Bill eligibility and markers of depression. Ann Epidemiol. 2016;26(2):129-35.

92. Seven M, Akyuz A, Sever N, Dincer S. Studying the Physical and Psychological Symptoms of Patients with Cancer. TAF Prev Med Bull. 2013; 12(3):219-24. doi:10.5455/pmb.1-1343053458.

93. Risal A, Manandhar K, Linde M, Steiner T, Holen A. Anxiety and depression in Nepal: prevalence, comorbidity and associations. BMC Psychiatry. 2016; 16(102):1-9.

94. Brandon TH. Negative affect as motivation to smoke. Current Directions in Psychological Science. 1994;3:33-7.

95. Kessler RC, Mc Gonagle KA, Zhao S, Hughes M, Eshleman S, Wittchen HU, Kendler KS. Lifetime and 12 month prevalence of DSMIII-R psychiatric disorder in the United States Result From the National Comorbidity Survey. Arch Gen Psychiatr. 1996;66:17-31.
96. Holländare F, Andersson G, Engström I. A comparison of psychometric properties between Internet and paper versions of two depression instruments (BDI-II and MADRS-S) administered to clinic patients. J Med Internet Res. 2010;12(5):49.

97. Nguyen DT, Dedding C, Pham TT, Wright P, Bunders J. Depression, anxiety, and suicidal ideation among Vietnamese secondary school students and proposed solutions: a cross-sectional study. BMC Public Health. 2013;13(1):1195.

\section{Submit your next manuscript to BioMed Central and we will help you at every step:}

- We accept pre-submission inquiries

- Our selector tool helps you to find the most relevant journal

- We provide round the clock customer support

- Convenient online submission

- Thorough peer review

- Inclusion in PubMed and all major indexing services

- Maximum visibility for your research

Submit your manuscript at www.biomedcentral.com/submit
C Biomed Central 